\title{
IR Spectra of Low-Metamorphosed Barzas Coal Subjected to Thermal Treatment in Carbon Dioxide Medium
}

\author{
Ivan Petrov ${ }^{1, *}$, Boris Tryasunov ${ }^{2}$, Konstantin Ushakov $^{2}$, and Alexander Bogomolov ${ }^{2,3}$ \\ ${ }^{1}$ Institute of Coal Chemistry \& Chemical Materials Science, Federal Research Center of Coal \& Coal \\ Chemistry, SB RAS, 650000 Kemerovo, 18 Sovetsky Ave., Russian Federation \\ ${ }^{2}$ T.F. Gorbachev Kuzbass State Technical University, Department of Heat Power Engineering, \\ 650000 Kemerovo, 28 Vesennyaya St., Russian Federation \\ ${ }^{3}$ Kutateladze Institute of Thermophysics, SB RAS, 630090 Novosibirsk, 1 Lavrentiev Ave., Russian \\ Federation
}

\begin{abstract}
Using FTIR spectroscopy, elemental analysis and gas chromatography methods, the temperature effects on the thermal transformations of low-metamorphosed Barzas coal (sapromixite) in carbon dioxide media have been studied. According to the IR spectroscopic data, an increase in the relative content of alkyl groups $\left(-\mathrm{CH}_{3}\right.$ and $>\mathrm{CH}_{2}$ ) in the solid residue of sapromixite with a rise in the process temperature up to $\sim 475^{\circ} \mathrm{C}$ was observed, followed by a rapid decrease in their concentration at higher heat treatment temperatures. Such behavior may be associated with an initial accumulation of alkyl fragments, formed from the coal matter, and their subsequent transition into the gaseous phase. A close relationship (an antibate dependence) has been discovered between $\mathrm{H} / \mathrm{C}$ atomic ratios in resin-containing solid products of thermally treated Barzas coal and the yields of gases formed during its pyrolysis. Chromatographic analysis of liquid products formed after Barzas coal heat treatment at $475^{\circ} \mathrm{C}$ showed that the main organic constituents of liquid phase (about $3-5 \%$ by weight) were phenol and its methyl- and dimethyl derivatives (their total content in methylene chloride extract was of $>77 \%$ by weight).
\end{abstract}

\section{Introduction}

Due to the depletion in the world's resources of cheap fossil liquid and gaseous hydrocarbons and the rise in the cost of their extraction, the problem of hydrocarbon shortage in world markets is becoming increasingly acute. The present situation makes researchers to look for ways to obtain chemicals and fuels from alternative sources. One possible solution for this problem is to obtain liquid or gaseous raw materials from available and cheap solid fuels, for example, from low-rank coals or pulverized wastes of coal-mining (coal dust). Currently, several approaches are used to convert solid fuels to

* Corresponding author: ipetrov@kemcity.ru 
liquid products: (i) coal pyrolysis accompanying high-temperature coke-making or mildtemperature char- or semicoke-making processes; (ii) indirect coal liquefaction (ICL) or, in other words, coal gasification with water steam for obtaining $\left(\mathrm{CO}+\mathrm{H}_{2}\right)$ mixtures (syngas) and their subsequent hydroprocessing to synthesize liquid products (hydrocarbons or oxygenates); (iii) direct coal by a hydrogen donor solvent containing aromatic compounds or with using another solvents [1-5].

Pyrolysis is the oldest method for obtaining liquids from coal; however, usually it provides low liquid yields and has comparatively low efficiency. Furthermore, the resulting liquids require further deep treatment before they can be used as commercial motor fuels or chemical products [4-7].

The ICL approach involves a complete breakdown of coal into other compounds by gasification. Resulting syngas is then modified to obtain the required balance of hydrogen and carbon monoxide. Later, after cleaning from sulfur and other impurities, syngas is reacted over appropriate catalysts to provide the desired products using Fischer-Tropsch or oxo-synthesis reactions [7-10]. Though all the ICL fuels and chemicals are inherently clean and virtually free from nitrogen, sulphur, heavy metal impurities and aromatics, generally giving relatively low emissions when combusted or used as reagents, the ICL method is a rather complicated multistage technology utilizing huge amounts of steam to break down coal into syngas, which is requiring substantial energy input [5].

The DCL method is built around a Bergius process splitting huge coal molecules into rather complicated mixtures of shorter hydrocarbons and resin-like species, resembling ordinary crude oil. This is realized by adding hydrogen to coal feedstock under high pressure and temperature $[6,10-13]$, thus eliminating the need for an intermediate carbonto-gas conversion present in the ICL technology. Processes of direct coal liquefaction are usually conducted at the temperatures of $400-600^{\circ} \mathrm{C}$ under high hydrogen pressure (15$20 \div 70-80 \mathrm{MPa}$ ) [1-3, 10-13]. For intensifying hydrogenation reactions and providing less severe conditions of coal conversion, these processes are often carried out in the presence of hydrogen-donor solvents (tetralin, alkyltetralins, phenanthrene and anthracene hydroderivatives, high-temperature fractions of oil and coal-derived products) with using relatively inexpensive catalysts (compositions on the base of iron, molybdenum, tungsten, zinc, nickel and cobalt compounds or their mixtures) [10-13].

One of the perspective directions for non-fuel use of low-rank and low-grade Kuzbass coals is their hydrogenation processing (DCL treatment) to produce artificial liquid fuels and valuable chemical components. In particular, the following low-metamorphosed coals present within the Kuznetsk coal basin can be used in the DCL process: 1) Barzas sapromixites; 2) brown coals of the Itatsky deposit (lignites); and 3) long-flame and gas coals from the deposits of Belovo and Leninsk-Kuznetsk areas of Kuzbass, in particular, long-flame coals of the Karakansky-Western coal mine. It has been found earlier [14] that among the above mentioned Kuzbass coals, Barzas sapromixite is the most promising for direct hydrogenation into liquid products.

According to modern ideas on the mechanism of direct coal liquefaction $[2,11,13]$, the process begins with the initial breakdown of coal into smaller fragments (radicals), which are then capped by hydrogen or polymerize to form char; this is a purely thermal decomposition of coal molecules, to which the catalysts used in the DCL technology do not have any relation. Because of an important role of this stage in forming coal liquefaction products, we tried to perform a comprehensive study of Barzas coal thermal decomposition processes in various media. In this paper, the results of IR spectroscopic, elemental and chromatographic analyses of both solid and liquid products formed during the thermal treatment of Barzas sapromixite in $\mathrm{CO}_{2}$ medium at various temperatures, are presented. 


\section{Experimental}

\subsection{Characteristics of Barzas sapromixite}

Basic characteristics of as-received Barzas sapromixite are listed in Table 1. Proximate analysis of this coal was carried out using conventional methods (GOST standards), and its ultimate analysis, as well as elemental analyses of its thermal treatment products, were performed with a Flash 2000 elemental analyzer (Thermo Fisher Scientific, USA).

Table 1. Characteristics of Barzas sapromixite studied.

\begin{tabular}{|c|c|c|c|c|c|c|c|c|c|}
\hline \multirow{2}{*}{$\begin{array}{c}\text { Coal } \\
\text { sample }\end{array}$} & \multicolumn{3}{|c|}{$\begin{array}{c}\text { Proximate analysis } \\
\text { (wt.\%) }\end{array}$} & \multicolumn{5}{|c|}{ Ultimate analysis (wt.\%, daf basis) } & \multirow{2}{*}{$\begin{array}{c}\mathrm{H} / \mathrm{C} \\
\text { atomic } \\
\text { ratio }\end{array}$} \\
\hline & $\mathbf{W}^{\mathrm{a}}$ & $\mathbf{A}^{\mathrm{a}}$ & $\mathbf{V}^{d a f}$ & $\mathbf{C}$ & $\mathbf{H}$ & $\mathbf{N}$ & $\mathbf{S}$ & $\begin{array}{c}O \text { (by } \\
\text { difference) }\end{array}$ & \\
\hline $\begin{array}{c}\text { Barzas } \\
\text { sapromixite }\end{array}$ & 4.2 & 22.2 & 64.0 & 82.74 & 8.83 & 0.54 & 1.22 & 7.33 & 1.28 \\
\hline
\end{tabular}

\subsection{Thermal treatment of Barzas sapromixite}

To study the process of thermal treatment of low-metamorphosed Barzas coal, a microreactor-autoclave (of $20 \mathrm{~cm}^{3}$ volume) was used to operate at high pressures and temperatures. The reactor with coal loaded and gaseous component $\left(\mathrm{CO}_{2}\right)$ introduced at various initial pressures was heated up to the temperatures in the range from 400 to $550^{\circ} \mathrm{C}$ and to the ending pressure in the system in the range from 7.0 to $11.0 \mathrm{MPa}$; heating rate of the samples in the reactor was of $10-12^{\circ} \mathrm{C} / \mathrm{min}$. The process temperature was controlled by a chromel-alumel thermocouple, and the pressure in the system was monitored by a manometer. An initial component of gaseous medium $\left(\mathrm{CO}_{2}\right)$ was pumped to the reactor through a fine adjustment needle valve. The process duration at a given temperature was of 20 minutes, after which the reactor was cooled to room temperature.

Three main types of products were formed as a result of Barzas sapromixite thermal treatment: 1) gaseous products; 2) resin-containing solid products and 3) small quantities (about 3-5 wt.\%) of liquid products representing aqueous solutions of organic substances (the latter ones were emerged only after sapromixite heat treatment at $475^{\circ} \mathrm{C}$ ). The amount of gas formed after the reactor cooling was measured using a drum counter; all the solid and liquid products remaining after the reaction were selecting, weighing and sending for IR and chromatographic analyses, respectively. Also, the concentrations of "coal liquids" (maltenes and asphaltenes) present in resin-containing solid products were determined by their sequential extraction in a Soxhlet apparatus. Chemically pure n-hexane (to isolate maltenes) and then analytically pure benzene (to separate asphaltenes and non-extractable residues) were used as the extractants. Preliminarily it was established that no maltenes and asphaltenes were contained in as-received Barzas coal. For each experiment, a material balance of the solid, liquid and gaseous products formed was determined.

\subsection{Characterization of Barzas sapromixite thermal treatment products}

A Fourier transform IR (FTIR) spectroscopy method was used to study the functional composition of solid products obtained after Barzas sapromixite thermal treatment; FTIR spectra of the samples studied were recorded with an Infralum FT-801 instrument (LumexSiberia, Russia) in the $500-4000 \mathrm{~cm}^{-1}$ spectral range using a $\mathrm{KBr}$ disk pressing technique.

Some amount of liquid products was formed after thermal treatment of Barzas coal at $475^{\circ} \mathrm{C}$ (solutions of organics in aqueous phase). Organic compounds dissolved in the 
aqueous phase of Barzas sapromixite pyrolysis products were analyzed by gas chromatography using an Agilent 6890N instrument (Agilent Technologies, USA) with a mass-selective Agilent 5973 detector. A capillary column (HP-5ms) being heated in a programmable temperature regime was employed for these analyses; organic products to analyze were extracted from the aqueous solution with methylene chloride.

\section{Results and Discussion}

FTIR spectra of Barzas sapromixite before and after its thermal treatments in carbon dioxide medium are presented in Fig. 1.

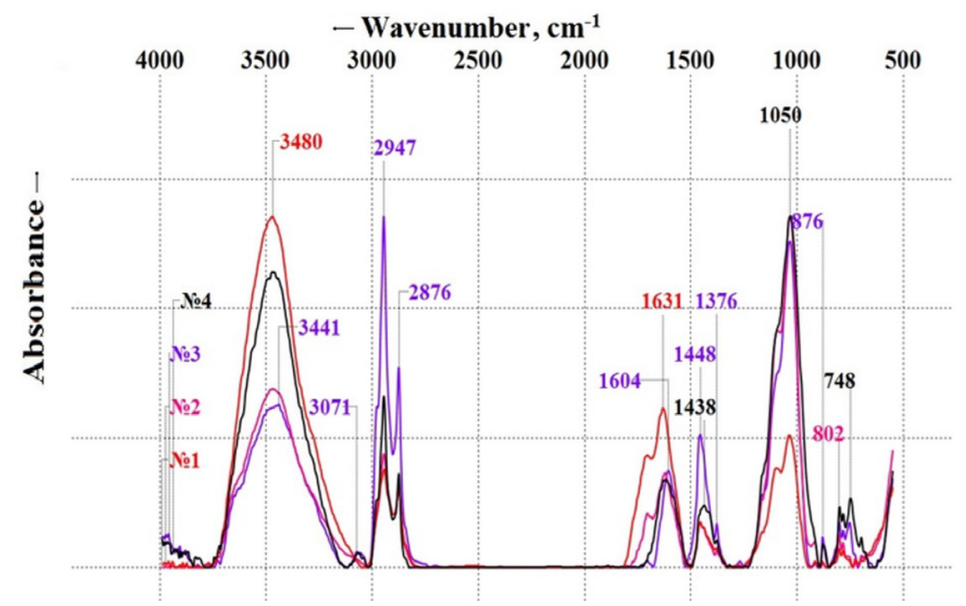

Fig. 1. FTIR spectra of Barzas sapromixite after its thermal treatment in $\mathrm{CO}_{2}$ medium at various temperatures: 1 - as-received coal; 2 - after $400^{\circ} \mathrm{C} ; 3$ - after $475^{\circ} \mathrm{C} ; 4-$ after $550^{\circ} \mathrm{C}$.

Taking into account the literature data on the IR spectra of various coals [15, 16], it can be concluded that the main groups of Barzas sapromixite sample IR absorption bands are manifested in the following frequency ranges: $3700-3200 \mathrm{~cm}^{-1}$ - stretching vibrations of hydrogen-bonded $\mathrm{OH}$ groups (with a maximum at $\sim 3480 \mathrm{~cm}^{-1}$ ); 3080-3020 $\mathrm{cm}^{-1}$ (stretching vibrations of aromatic C-H groups); $2920-2960 \mathrm{~cm}^{-1}$ with a maximum about $2947 \mathrm{~cm}^{-1}$ (stretching vibrations of methylene $>\mathrm{CH}_{2}$ groups and asymmetric stretching vibrations of $\mathrm{CH}_{3}$ groups); $2860-2880 \mathrm{~cm}^{-1}$ (symmetric stretching vibrations of $\mathrm{CH}_{3}$ groups); an intensive absorption band at $\sim 1600 \mathrm{~cm}^{-1}$ (stretching vibrations of aromatic $\mathrm{C}=\mathrm{C}$ groups) partially overlapping with an absorption band of water deformation (bending) vibrations $\left(\delta_{\mathrm{H}-\mathrm{O}-\mathrm{H}}\right)$, manifested in the $\sim 1630-1650 \mathrm{~cm}^{-1}$ region; an absorption band at $\sim 1700 \mathrm{~cm}^{-1}$ (stretching vibrations of carbonyl $\mathrm{C}=\mathrm{O}$ groups); absorption bands in the $1450-1430 \mathrm{~cm}-1$ (bending vibrations of $\mathrm{CH}_{2}$ groups and asymmetric deformation vibrations of $\mathrm{CH}_{3}$ groups) and $1380 \mathrm{~cm}^{-1}$ (symmetric deformation vibrations of $\mathrm{CH}_{3}$ groups) regions; an absorption band in the $1200-1100 \mathrm{~cm}^{-1}$ region (stretching vibrations of $\mathrm{C}-\mathrm{O}-\mathrm{H}$ groups); a group of absorption bands in the $1080-1020 \mathrm{~cm}^{-1}$ interval with a maximum at $\sim 1050 \mathrm{~cm}^{-1}$ (stretching vibrations of bridging ether C-O-C groups); a group of absorption bands in the $700-900 \mathrm{~cm}^{-}$ ${ }^{1}$ range that are associated with out-of-plane vibrations of aromatic ring $\mathrm{C}-\mathrm{H}$ bonds.

To quantify the changes in intensity of IR absorption bands, the absorption band of aromatic $\mathrm{C}=\mathrm{C}$ groups in the range of $1600 \mathrm{~cm}^{-1}$ was chosen as a reference comparison band, since its intensity (optical density) decreases slightly only at the first stages of heat treatment of coal samples $\left(<400^{\circ} \mathrm{C}\right)$, and then it practically does not change with increasing pyrolysis temperature. 


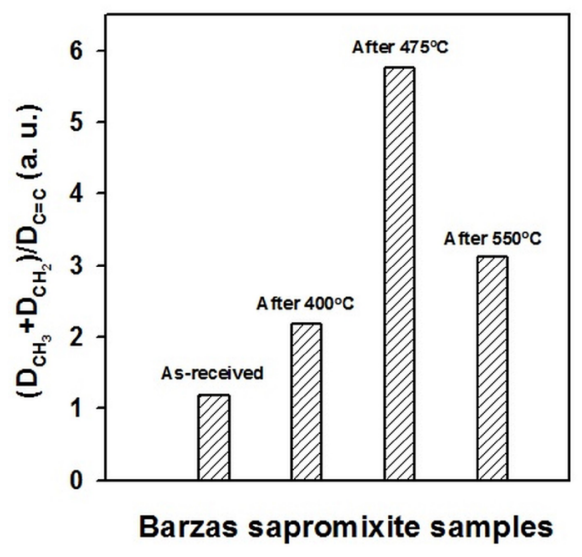

Fig. 2. Temperature effects on the relative intensities of IR absorption bands associated to alkyl groups in the FTIR spectra of Barzas sapromixite after its thermal treatments in $\mathrm{CO}_{2}$ medium

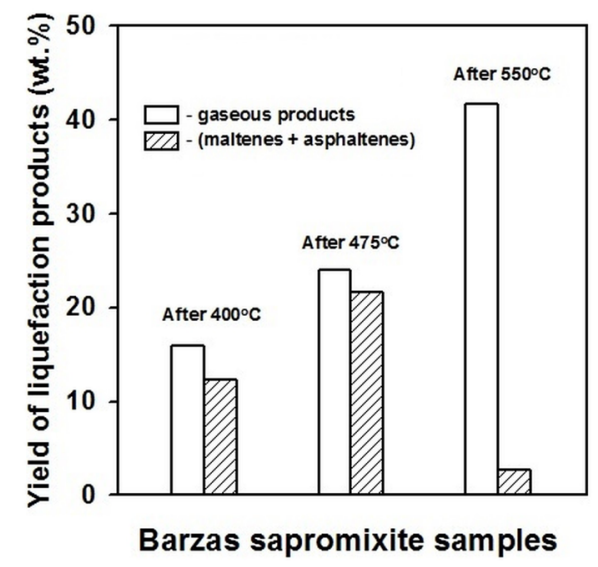

Fig. 4. Temperature effects on the yields of liquefaction products (calculated on the $d a f$ basis) during thermal treatment of Barzas coal in $\mathrm{CO}_{2}$ medium

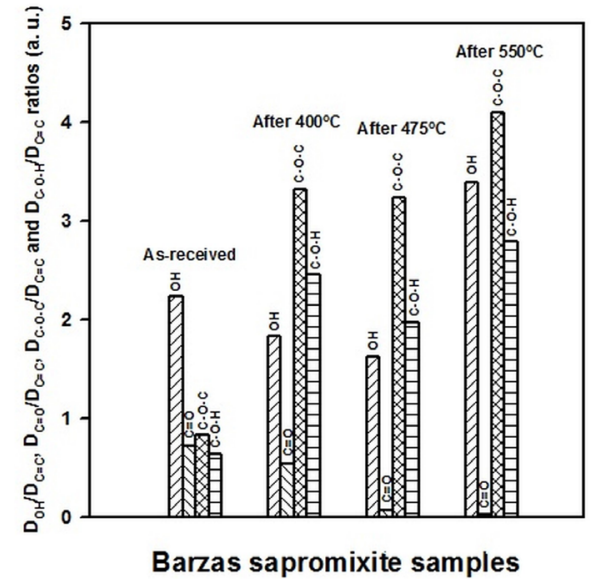

Fig. 3. Temperature effects on the relative intensities of the IR absorption bands associated to some oxygen-containing functional groups in the FTIR spectra of Barzas sapromixite after its thermal treatments in $\mathrm{CO}_{2}$ medium

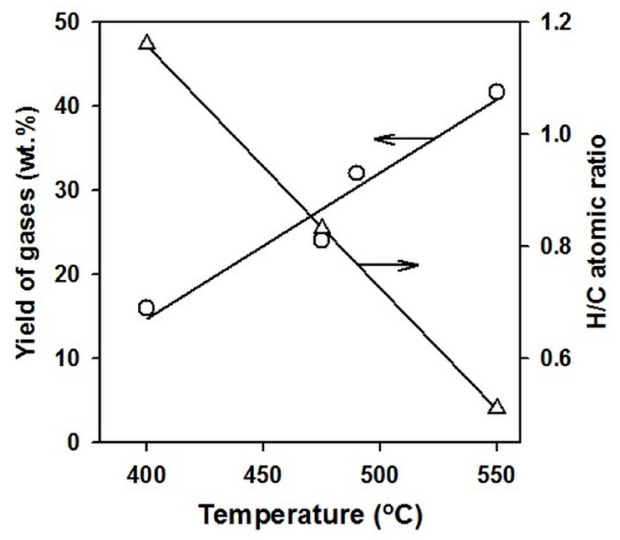

Fig. 5. Temperature effects on the gas yields (calculated on the daf basis) and $\mathrm{H} / \mathrm{C}$ atomic ratios in the solid resin-containing products of Barzas coal thermally treated in $\mathrm{CO}_{2}$ medium

During the thermal treatment of Barzas coal, the intensities of alkyl and oxygencontaining functional groups were changing the most drastically. Therefore, the relative intensities (optical densities) of alkyl groups (the sum optical densities of $\mathrm{CH}_{3}$ and $\mathrm{CH}_{2} \mathrm{IR}$ absorption bands normalized to the optical density of the $1600 \mathrm{~cm}^{-1}$ band, i.e., $\left(\mathrm{D}_{2947}\right.$ $\left.+\mathrm{D}_{2876}\right) / \mathrm{D}_{1600}$ ratios), as well as relative intensities of hydroxyl groups $\left(\mathrm{D}_{3480} / \mathrm{D}_{1600}\right.$ ratios $)$, carbonyl groups $\left(\mathrm{D}_{1700} / \mathrm{D}_{1600}\right.$ ratios $), \mathrm{C}-\mathrm{O}-\mathrm{H}$ groups $\left(\mathrm{D}_{1200} / \mathrm{D}_{1600}\right.$ ratios $)$ and $\mathrm{C}-\mathrm{O}-\mathrm{C}$ groups $\left(\mathrm{D}_{1050} / \mathrm{D}_{1600}\right.$ ratios) were selected as the main parameters for quantitative assessment of the changes occurring in the Barzas sapromixite samples after their thermal treatment in $\mathrm{CO}_{2}$ medium. The results of these quantitative evaluations are presented in Figs. 2,3.

Data obtained indicate a noticeable increase of alkyl groups absorption intensities with an increase in the pyrolysis temperature to $475^{\circ} \mathrm{C}$ (Fig. 2), obviously connected with 
intense formation of paraffin-naphthenic structures appearing during the process studied. However, at the higher heat treatment temperatures, the relative content of these groups in the sample decreases (Fig. 2), which can be explained by detachment of alkyl fragments from carbon matrix and by their subsequent transition to the gaseous phase. Indeed, at $\mathrm{T}=$ $550^{\circ} \mathrm{C}$ the yield of gases drastically increases, while the content of "coal liquids" (maltenes + asphaltenes) and $\mathrm{H} / \mathrm{C}$ atomic ratio in resin-containing thermally treated product significantly decrease (see Figs. 4 and 5). In fact, a clear antibate dependence takes place between yields of gases formed and $\mathrm{H} / \mathrm{C}$ atomic ratios in resin-containing solid products (Figs. 4 and 5). At the same time, both the yields of "coal liquids" (Fig. 4) and IR intensities of alkyl groups (Fig. 2) go through a maximum at $475^{\circ} \mathrm{C}$ with temperature rising.

Table 2. Concentrations of organic components in aqueous phases of Barzas sapromixite after its thermal treatment at $475^{\circ} \mathrm{C}$ in $\mathrm{CO}_{2}$ medium

\begin{tabular}{|c|c|c|}
\hline $\begin{array}{c}\text { Retention time } \\
\text { (min) }\end{array}$ & Component & $\begin{array}{c}\text { Relative concentration } \\
\text { (wt. \%) }\end{array}$ \\
\hline 2.035 & Propanoic acid & 3.596 \\
2.089 & 2-Pentanone & 0.770 \\
2.382 & Propanoic acid, 2-methyl- & 0.749 \\
2.492 & Pyridine & 1.330 \\
2.644 & Butanoic acid & 3.716 \\
2.839 & Cyclopentanone & 3.875 \\
3.156 & Pyridine, 2-methyl- & 1.253 \\
3.412 & Cyclopentanone, 2-methyl- & 0.566 \\
3.827 & Pentanoic acid & 1.950 \\
4.070 & Pyridine, 2,6-dimethyl- & 0.503 \\
4.223 & Cyclohexanone & 1.356 \\
4.430 & Unidentified & 0.612 \\
4.546 & Butyrolactone & 0.464 \\
5.326 & 2(3H)-Furanone, dihydro-5-methyl- & 0.709 \\
5.558 & Pyridine, 2-ethyl-6-methyl- & 0.446 \\
5.777 & Phenol & 39.295 \\
6.643 & p-Benzoquinone, 2-methyl- & 0.546 \\
7.289 & Unidentified & 0.405 \\
7.545 & Phenol, 2-methyl- & 14.663 \\
8.069 & p-Cresol & 16.052 \\
8.934 & Phenol, 2,5-dimethyl- & 0.817 \\
9.739 & Phenol, 2-ethyl- & 1.147 \\
10.013 & Phenol, 2,4-dimethyl- & 3.187 \\
10.580 & Phenol, 3-ethyl- & 1.072 \\
10.824 & Phenol, 2,6-dimethyl- & 0.480 \\
16.316 & Unidentified & 0.441 \\
\hline
\end{tabular}

Analysis of relative intensities of the IR absorption bands of oxygen-containing groups in the solid products of Barzas sapromixite thermal treatment (Fig. 3) indicates the complex nature of its thermal transformations during pyrolysis in $\mathrm{CO}_{2}$. While the intensities of $\mathrm{C}=\mathrm{O}$ groups absorption bands continuously decrease with increasing heat treatment temperature, the intensities of the $\mathrm{C}-\mathrm{O}-\mathrm{C}$ and $\mathrm{C}-\mathrm{O}-\mathrm{H}$ group IR absorption bands first increase (at $\mathrm{T}=$ $\left.400^{\circ} \mathrm{C}\right)$, then slightly decrease $\left(\mathrm{T}=475^{\circ} \mathrm{C}\right)$, and, at last, again increase at $550^{\circ} \mathrm{C}$. Relative intensity of the hydroxyl groups decreases noticeably with an increase in the pyrolysis temperature to $475^{\circ} \mathrm{C}$, and then sharply increases after heat treatment at $\mathrm{T}=550^{\circ} \mathrm{C}$ (Fig. 3). Complicated dependences for IR intensities of oxygen-containing groups may be caused by redistribution of a part of oxygen present in $\mathrm{C}=\mathrm{O}$ and $\mathrm{O}-\mathrm{H}$ groups, due to its transition to bridged $\mathrm{C}-\mathrm{O}-\mathrm{C}$ and $\mathrm{C}-\mathrm{O}-\mathrm{H}$ structures. 
According to chromatographic analysis data (see Table 2), among the organic components (predominantly oxygen-containing substances) identified in the aqueous phases of Barzas coal thermal treatment products, the most valuable compounds were phenol and its methyl- and dimethyl derivatives (cresols and xylenols). Relative total concentration of these monoaromatic phenols in methylene chloride extract was of $>77 \%$, with phenol content exceeding 39\%. Besides that, linear and cyclic ketones (pentanone, cyclopentanone, cyclohexanone, butyrolactone, derivatives of furanone and benzoquinone), as well as pyridine and low molecular weight organic acids (propanoic acid and its methyl derivatives, butanoic and pentanoic acids), have been fixed in the composition of coal pyrolysis liquid phase products. In future we are planning a study of thermal behavior of Barzas sapromixite in $\mathrm{H}_{2}$ medium (including some experiments in the presence of catalysts and hydroaromatic solvents), as well as more comprehensive investigations of Barzas coal liquefaction products and their possible conversions into commercial fuels and chemicals.

\section{References}

1. J.G. Speight, The chemistry and technology of coal, 3rd ed. (CRC Press, Taylor \& Francis Group, Boca Raton-London-New York, 2013)

2. C. Burgess Clifford, C. Song, In: Advances in clean hydrocarbon fuel processing (Ed. by M. Rashid Khan) (Woodhead Publ. Ltd., New Delhi, 2011)

3. A.S. Maloletnev, M.Ya. Shpirt, Russ. J. Gen. Chem. 79, 2499 (2009)

4. K.-C. Xie, Structure and reactivity of coal: a survey of selected Chinese coals (Springer-Verlag, Berlin-Heidelberg, 2015)

5. M. Hook, K. Aleklett, Int. J. Energy Res. 34, 848 (2010)

6. M. Granda, C. Blanco, P. Patricia, J.W. Patrick, R. Menendez, Chem. Rev. 114, 1608 (2014)

7. Q. You, S.-Y. Wu, Y.-Q. Wu, S. Huang, J.-S. Gao, J.-X. Shang, Fuel Process. Technol. 156, 54 (2017)

8. E. Jin, Y. Zhang, L. He, H. Gordon Harris, B. Teng, M. Fan, Appl. Catal. A. 476, 158 (2014)

9. J. Xu, Y. Yang, Y.-W. Li, Fuel 152, 122 (2015)

10. C. Higman, S. Nam, Chem. Rev. 114, 1673 (2014)

11. I. Mochida, K. Sakanishi, Adv. Catal. 40, 39 (1994)

12. S. Vasireddy, B. Morreale, A. Cugini, C. Song, J.J. Spivey, Energy \& Environ. Sci. 4, $311(2011)$

13. I. Mochida, O. Okuma, S.-H. Yoon, Chem. Rev. 114, 1637 (2014)

14. I.Y. Petrov, B.G. Tryasunov, E3S Web of Conferences 21, 01004 (2017)

15. P.R. Solomon, In: Advances in coal spectroscopy Springer Science + Business Media, New York, 1992)

16. P.R. Solomon, D.G. Hamblen, In: Chemistry of coal conversion (Springer Science + Springer Media, LLC, New York, 1985) 